\title{
Finding the Right Balanced Scorecard for Business-Driven IT Management A Literature Review
}

\author{
Andreas Györy \\ University of St.Gallen \\ andreas.gyoery@unisg.ch
}

\author{
Walter Brenner \\ University of St.Gallen \\ walter.brenner@unisg.ch
}

\author{
Falk Uebernickel \\ University of St.Gallen \\ falk.uebernickel@unisg.ch
}

\begin{abstract}
During the last decades information technology (IT) management has changed significantly. Starting from being a costly and rare resource in its very beginnings IT has evolved into a vital enabler for almost any kind of business today. This development demands for highly flexible management concepts allowing the business to actively control and govern IT performance. A meanwhile widely used approach for multi-dimensional performance measurement in the context of IT management is the Balanced Scorecard (BSC). With this article we aim at investigating the state of the art of IT BSC use through a comprehensive literature analysis. Moreover, we evaluate the adaptability of the different types of this concept to the most recent developments in IT management. Our findings suggest that two new scorecards need to be derived: the IT BSC for services and service portfolios.
\end{abstract}

\section{Introduction}

IT management has evolved significantly since its early stages and is just now about to undergo yet another evolutionary step. Initiating from the reactive "firefighting" on an individual infrastructure device level (resource orientation), it grew into the management of domains of resources (domain orientation) and has now reached the stage where endto-end services are designed and operated proactively to fulfill user requirements (user orientation) [11, 32]. Today's IT service management (ITSM) frameworks (e.g., ITIL [6] and ISO/IEC 20000 [21]) address the challenges associated with implementing standardized and automated service portfolios spanning multiple technological silos [66]. "However, ITSM is mostly using technical metrics" [47] while "in order for IT to help the business achieve its goals, ITSM decisions must be steered by business-oriented measures and objectives" [4]. This caused the further development of ITSM to evolve towards a "Business-driven IT Management" (BDIM) or "Business Service
Management" (BSM) [47] heralding the beginning of business orientation. BSM essentially "is ITSM with business metrics. [...] This allows IT-related decisions to be taken from a business perspective" [47]. To achieve this, BSM extends current ITSM approaches by a business process centric view (through the use of business process metrics) $[4,11,23,32,40,47]$ and dynamic cause and effect models between IT resources, services, and business processes [4, 32, 36, $37,40,47]$. The increasing number of vendors offering BSM supporting tools [41] and the growing adoption of business-oriented IT management processes and techniques [37] indicate the present importance of BSM for practitioners. Simultaneously researchers have developed a framework, that outlines future fields of IS research supporting the development of BSM [44].

However, the central aspect of BSM, the linkage of business and IT metrics for alignment and cost justification purposes, has been addressed by concepts like the BSC for IT, applied information economics and earned value management since almost two decades [10]. The novelty today is that the maturation of Business Process Management (BPM) has enabled the linkage of business processes to IT services [44]. It now becomes possible to evaluate the cause and effect relations of IT and business performance not from a holistic departmental view but on the business process and IT services level at reasonable cost. At this point the question arises to what extent holistic management concepts can and have been applied to leverage this new possibility. To address this question we focus on the concept of the BSC, which has turned out to be valuable for comprehensively measuring business and IT performance metrics. The success of the BSC in IT is indicated by a survey of The Working Council for Chief Information Officers which reported in 2003 that 39 percent of 124 selected international companies were using this technique [67]. Independently, a study of the CIO magazine shows that among 345 senior IT executives the BSC has been adopted by an increased number of companies (2002: 24\%, 2003: 30\%) [67]. The success of the BSC in IT is due to its flexible 
design and comprehensive nature. It allows for monitoring multiple perspectives (including technical and corporate) simultaneously and offers cause and effect relations between metrics and perspectives through its strategy map [35]. The possibility of using a cascade of BSCs across multiple organizational levels supports strategic alignment [62]. Because of its easy adaptability the BSC has been applied in IT not only to evaluate departments $[46,49,54,55]$ but also in IT Governance $[56,59]$, IT operations subdivisions $[60,62]$, IT development subdivisions [13, 33], Information Systems (IS) [17, 43, 45], and IT/IS projects $[2,3]$. The adaption of BSCs in IT has been fueled by the development of a generic BSC for IT [60] and a maturity model for implementing BSCs in IT [61]. From this point on this article employs the term "IT BSC" to reference all available adaptations of the BSC within the IT/IS domain.

Given the extensive use of the IT BSC and the currently advancing topic of BSM, this review contributes to the adaption of the IT BSC to BSM by addressing the following questions:

1. What is the state-of-the-art in IT BSCs?

2. Which are the relevant types of IT BSCs for BSM?

Previous reviews have addressed the evolution of the IT BSC [10], performance management frameworks [1] and capital investment-appraisal techniques [39] thus describing performance management from a generic viewpoint. As of today, only one article, written in 2001, has been identified to address the differences in IT BSC applications [48]. Since this review has been conducted ten years ago it does not reflect the current state-of-the-art. Hence, the review at hand aims to update the existing research results and extend them with focus on the adaptability of IT BSCs to BSM.

This paper proceeds as follows: The next section introduces the applied research methodology. This is followed by the synthesis of the research findings in section three. Subsequently, the findings are discussed and a research agenda is proposed. The paper concludes with a brief summary, limitations and an outlook on future work.

\section{Research methodology}

To identify the state-of-the-art in IT BSCs, we utilize the method of a systematic literature review as suggested and used by many senior scholars (e.g., [4, $9,16,31,65,66])$. The process described by vom
Brocke [64] consists of five steps: (1) Definition of review scope, (2) conceptualization of the topic, (3) literature search, (4) literature analysis and synthesis, (5) research agenda. This section describes steps (1)(3) while (4) and (5) are presented in the following chapters.

\subsection{Review scope}

Before conducting the literature review we clearly defined the boundaries of our endeavor. We did this by applying the established taxonomy suggested by Cooper [9]. This taxonomy contains six constitutive characteristics as shown in Figure 1. Each characteristic contains certain categories. Thereby focus, goal, organization and audience can be independently combined, while perspective and coverage are mutually exclusive [64].

Figure 1 shows the characteristics of the review we provide in this article. The focus lies on identifying the applications of BSC in IT within scientific literature with the goal of integrating their central aspects. We organize the body of knowledge historically in Figure 3 and conceptually in Figure 4 while describing it from a neutral perspective. This allows general scholars to see the big picture of IT BSC applications and specialized scholars and practitioners to find available solutions relevant to their work. Although we aim to be as exhaustive as possible within the boundaries of our review, the literature we examined is just a grain of sand compared to the available sandcastle of knowledge. Hence, this review has a representative character.

\begin{tabular}{|c||c|c|c|c|}
\hline \multicolumn{1}{|c|}{$\begin{array}{c}\text { Charac- } \\
\text { teristics }\end{array}$} & \multicolumn{4}{|c|}{ Categories } \\
\hline \hline Focus & $\begin{array}{c}\text { Research } \\
\text { Outcomes }\end{array}$ & $\begin{array}{c}\text { Research } \\
\text { Methods }\end{array}$ & Theories & Applications \\
\hline \hline Goal & Integration & \multicolumn{2}{|c|}{ Criticism } & Central Issues \\
\hline \hline Organisation & Historical & Conceptual & Methodological \\
\hline \hline Perspective & Neutral Representation & Espousal of Position \\
\hline \hline Audience & $\begin{array}{c}\text { Specialized } \\
\text { Scholars }\end{array}$ & $\begin{array}{c}\text { General } \\
\text { Scholars }\end{array}$ & Practitioners & General Public \\
\hline \hline Coverage & Exhaustive & $\begin{array}{c}\text { Exhaustive \& } \\
\text { Selective }\end{array}$ & Representative & Central/Pivotal \\
\cline { 3 - 5 } & &
\end{tabular}

Figure 1. Review Scope

\subsection{Conceptualization of the topic}

The IT BSC has been derived from the original BSC by multiple authors $[35,55]$. Originally, the BSC has been developed by Kaplan and Norton in 1992 to give corporate "managers complex information at a glance" including more than just financial measures [24]. The original design encompasses four 


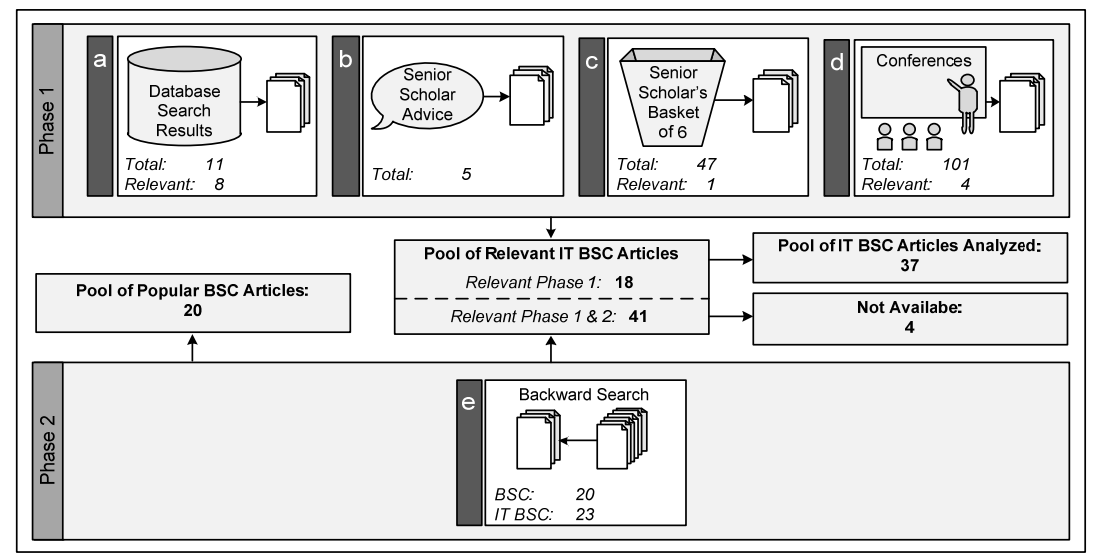

Figure 2. Literature search process

perspectives (customer, internal business, innovation and learning, and financial) each containing typically 15 to 20 measures [34]. By adding or altering individual measures and perspectives the BSC can be tailored to suite the strategy of any organization [14]. It has subsequently been enhanced by Kaplan and Norton through the inclusion of a method to strategically align and develop its measures [25] and strategy maps [27]. Today, a full-featured BSC may contain: An overall vision and strategy, a strategy map, and different performance perspectives containing key performance indicators (KPIs). The overall vision sets the long term goal the enterprise strives to achieve, while the derived strategy describes how this goal is going to be reached. The perspectives and measures are designed to reflect how well the strategy is implemented within the organization. Each perspective may contain a perspective-centric goal, initiatives, and measures. Each measure may contain: A current value, a target value, and a benchmark value. The assumptions of cause and effects that are made during strategy formulation may be described in a strategy map. This links operational and strategic measures and or perspectives according to their expected interrelations.

To assess the extent to which business and IT metrics are linked within different kinds of IT BSC publications, this review focuses on identifying available perspectives, business and IT metrics, and strategy maps. Additionally, we summarize the objectives for implementing IT BSCs and the subjects that are being evaluated through the use of an IT BSC (see results in Figure 4).

\subsection{Literature search}

To cover the vast amount of available knowledge we conducted a two phase approach as depicted in Figure 2:
1. We addressed the articles directly available through a primary source (step $\mathrm{a}-\mathrm{d}$ )

2. Conducting a backward references search, we identified and analyzed the references of the relevant articles from step 1 (step e).

In the first step we collected a basket of 18 relevant articles through four different sources, namely: a) database search, b) articles advised by senior scholars, c) AIS Senior scholars' basket of six journal search, d) international conference proceedings search. With our diversity of sources we addressed following challenges: (1) Often IT/IS is being evaluated by BSCs outside of the typical IT/IS domain (e.g. construction industry [52]) ( $\rightarrow$ database search), (2) leading journals have a lag of time from writing till publishing ( $\rightarrow$ conference search), (3) a rigorous search by keywords often does not include already available literature ( $\rightarrow$ seniors scholar advice) and (4) capturing the mainstream IT research streams $(\rightarrow$ AIS senior scholars' basket of six journal search).

For the three searches we use the following keywords: (1) "Information Technology", (2) "Information Technologies", (3) "Information System", and (4) "Balanced Scorecard". Keywords were combined with following logic: (1 OR 2 OR 3) AND 4. This allowed us to identify literature concerning IT and the BSC at the same time. Drawing on results of exploratory searches preceding this review we excluded the acronyms "IT", "IS", and "BSC" from our keywords. This is due to the fact that many search engines interpret "IT" as "it" and "IS" as "is" (e.g. Ebscohost), while the term "BSC" carries multiple meanings besides "Balanced Score Card" (e.g. "binary symmetric channel" [8] or "best supportive care" [42]). To filter irrelevant articles at an early stage and to offer consistent search results across the different databases we only used full terms as keywords. 
Every search result was first cleansed from duplicates (including previous results) and then filtered according to two criteria to assure that a contribution to the research question can be derived: (1) only articles that were written or translated into English and (2) only articles concerning the adaption of the BSC for IT evaluation and not the use of IT in implementing a BSC were considered relevant. The authors note that articles suggesting alternative frameworks but drawing a parallel to the IT BSC were also included.

The database search (conducted on March $19^{\text {th }}$, 2011) encompassed the following databases: Ebscohost, Proquest, ISI Web Of Knowledge, JStor, and ScienceDirect. The query encompassed all available journals, without a limitation to the field of IT/IS. The keyword combination (described above) was required to appear in the title, the subject or keywords, and the abstract of each article. The strict restriction of the keywords appearing in all fields allowed us to focus on articles most likely to be relevant while searching through a multitude of domains. This yielded a total of eleven results of which eight were considered relevant.

The AIS senior scholars' basket of six includes the major journals of the IS field, namely: (1) European Journal of Information Systems (EJIS), (2) Information Systems Journal (ISJ), (3) Information Systems Research (ISR), (4) Journal of AIS (JAIS), (5) Journal of MIS (JMIS) and (6) MIS Quarterly (MISQ).

The search (conducted on the $30^{\text {th }}$ of March, 2011) was carried out with the keyword combination required to appear anywhere in the full text of the articles. Due to the fact that this search was limited to IS journals the less rigid keyword search (full text search) has been chosen to grasp the full extent to which this topic has been discussed in the IS domain. However, out of 47 hits in total only one article [54] passed the filter criteria described previously. (The authors note that this article has been identified through the database search as well but has been accounted for within step c).

On the same day, we also conducted the search of international conference proceedings. For this we included the following established international conferences in the IS domain: a) Hawaiian International Conference on System Sciences (HICSS), b) European Conference On Information Systems (ECIS), c) International Conference On Information Systems (ICIS), and d) Americas Conference on Information Systems (AMCIS). Again, moving within the IT/IS domain we required the articles to contain the keyword combination anywhere in their full text. This yielded a total of 101 hits out of which four passed the filtering requirements, as most articles were concerned with IT support for a BSC and not an IT BSC.
Finally, we also included five articles using the BSC for IT evaluation suggested by senior scholars.

The unfiltered results of the basket after the first phase hence contained a total of 166 , while after filtering we were left with 18 .

To also find the articles relevant but outside the reach of our primary sources, a backward literature search has been conducted (as suggested by [9, 30, 64]), departing from the initial 18 articles. To identify also the frequently cited core BSC articles only the keyword "Balanced Scorecard" in the title of the referenced literature was accounted for. Through this procedure we identified 43 additional articles out of which 23 were applying the BSC within IT and 20 were focusing purely on the BSC. The final basket of literature therefore contains 61 articles out of which 38 are analyzed in detail within the next section. For completeness, the authors note that this number reflects the fact that four sources $[7,12,16,63]$ were not available to the authors during the time of research.

\section{Synthesis of the research findings}

Before elaborating on the available IT BSCs we highlight the most frequently cited BSC literature within the reviewed basket of articles. This supplies novice researcher with the basic references that allow the understanding of the BSC concept and its development. Furthermore, as these articles are the most common sources cited, they offer the foundation to conduct future forward searches (as described in [30]) in the field of the BSC as well as its applications in the IT/IS domain. The top four publications are depicted in Table 1. Although a complete citation map has been created, it has not been included due to page count limitations but may be requested from the authors.

Having identified the core BSC articles we continue to review the literature concerning the IT

Table 1. Foundation of BSC literature

\begin{tabular}{|c|l|c|c|}
\hline Citations & \multicolumn{1}{|c|}{ Title } & Year & Ref. \\
\hline $34 / 66$ & $\begin{array}{l}\text { The Balanced Scorecard: } \\
\text { Translating Strategy Into } \\
\text { Action }\end{array}$ & 1996 & {$[26]$} \\
\hline $32 / 66$ & $\begin{array}{l}\text { The balanced scorecard: } \\
\text { Measures that drive } \\
\text { performance }\end{array}$ & 1992 & {$[24]$} \\
\hline $13 / 66$ & $\begin{array}{l}\text { Using the balanced } \\
\text { scorecard as a strategic } \\
\text { management system }\end{array}$ & 1996 & {$[27]$} \\
\hline $12 / 66$ & $\begin{array}{l}\text { Putting the Balanced } \\
\text { Scorecard to Work }\end{array}$ & 1993 & {$[25]$} \\
\hline
\end{tabular}




\begin{tabular}{|c|c|c|c|c|c|c|c|c|}
\hline Characteristics & \multicolumn{8}{|c|}{ Categories } \\
\hline Time Span & \multicolumn{3}{|c|}{$\begin{array}{c}1994-1999(6) \\
{[15,20,35,45,54,55]}\end{array}$} & \multicolumn{3}{|c|}{$\begin{array}{c}2000-2005(\mathbf{2 6}) \\
{[1,3,13,17-19,28,31,33,38,39,43} \\
46,48-50,52,53,56-62,67]\end{array}$} & \multicolumn{2}{|c|}{$\begin{array}{c}2006+(5) \\
{[2,10,14,22,29,59]}\end{array}$} \\
\hline Region & $\begin{array}{c}\text { Europe (14) } \\
{[3,14,20,39,50,54-} \\
62]\end{array}$ & \multicolumn{2}{|c|}{$\begin{array}{c}\text { Americas (14) } \\
{[1,10,13,15,17-19} \\
22,28,33,46,49 \\
52,67]\end{array}$} & \multicolumn{2}{|c|}{$\begin{array}{c}\text { Asia (3) } \\
{[2,29,35]}\end{array}$} & \multicolumn{2}{|c|}{$\begin{array}{c}\text { Australia (5) } \\
{[31,43,45,48,53]}\end{array}$} & $\begin{array}{c}\text { Africa (1) } \\
\text { [38] }\end{array}$ \\
\hline Outlet Type & \multicolumn{2}{|c|}{$\begin{array}{c}\text { Journal Article (20) } \\
{[1-3,10,17,19,22,29,33,} \\
35,39,46,49,50,52-54 \\
56,57,59]\end{array}$} & \multicolumn{2}{|c|}{$\begin{array}{c}\text { Conference Proceeding (8) } \\
{[14,18,31,45,48,55,58} \\
60]\end{array}$} & \multicolumn{2}{|c|}{$\begin{array}{r}\text { Book (3) } \\
{[13,28,38,43,}\end{array}$} & & $\begin{array}{c}\text { Other (3) } \\
{[15,20,67]}\end{array}$ \\
\hline
\end{tabular}

Figure 3. Demographic conceptual matrix of 37 articles

BSC. To summarize the data of our findings in a compact way we use two conceptual matrices [65] containing different characteristics: (1) demographic characteristics and (2) content related characteristics. To make this data more easily accessible we synthesize the date in the following chapter in form of a timeline (see Figure 5). The following paragraph briefly explains the applied characteristics of the matrices, while the results are outlined in Figure 3 and Figure 4. Where detailed results are necessary references are explicated within the text.

The demographic analysis - summarized in Figure 3 - explores the origins of the articles by three mutually exclusive characteristics. We hence include for each article the time span it was published in, the regional origin of writing and the type of outlet it was published in. To offer an easy overview, broad categories have been chosen. It has to be noted that the chapters $[13,43,61]$ are from the same book and are therefore accounted only as one element within the category "Book".

The second matrix categorizes the publications by their content, allowing us to compare the characteristics available BSCs. The results of this classification are presented in Figure 4.

Our first goal was to identify IT BSCs within the available literature. Therefore, we separated publications according to the artifacts they contain (articles containing more than one artifact appear in multiple categories). We distinguished generic IT BSCs, to determine the fundament for further BSC adaption, from applied IT BSCs, which serve as a source of KPIs. Additionally, we identified methods and maturity models for IT BSCs and filtered reviews and alternate frameworks from further evaluation.

Since IT BSCs differ widely in their application we secondly categorized the articles according to the subject of the described BSC to identify the closest match for a BSM application. While IT BSCs in most cases are applied to manage the performance of an IT department, they are also used to manage certain subfunctions like IT Governance [56], Software Development [20] or Service Level Management (SLM) [57] (summarized under "IT Function"). Furthermore, they are employed to support evaluation of IT projects and recently also IT project portfolios. IT BSCs are additionally applied to support the management of investment intensive IS (such as Human Resources (HR) systems [17], Enterprise Resource Planning (ERP) systems [43, 45] and webservices [19]).

A further aspect of the diverse usage of IT BSCs becomes visible if one outlines the goals of these scorecards. The most commonly described purpose is the usage as tool for monitoring, measuring, evaluating, and reporting performance (summarized under "Evaluation"). Closely related are publications suggesting the BSC's use for performance improvement. Some articles suggest a usage as business IT alignment tool, while others see BSCs as

Table 2. Mapping of traditional perspectives

\begin{tabular}{|c|c|c|}
\hline $\begin{array}{l}\text { Original } \\
\text { BSC [24] }\end{array}$ & $\begin{array}{c}\text { Generic IT BSC } \\
{[60]}\end{array}$ & $\begin{array}{l}\text { Mapped } \\
\text { Perspectives }\end{array}$ \\
\hline Financial & $\begin{array}{c}\text { Business } \\
\text { Contribution }\end{array}$ & $\begin{array}{l}\text { - Corporate } \\
\text { Contribution [60] } \\
\text { - Benefits [53] }\end{array}$ \\
\hline Customer & $\begin{array}{c}\text { User } \\
\text { Orientation }\end{array}$ & $\begin{array}{l}\text { - Client \& Community } \\
\text { relationships" [48] }\end{array}$ \\
\hline $\begin{array}{l}\text { Internal } \\
\text { Process }\end{array}$ & $\begin{array}{l}\text { Operational } \\
\text { Excellence }\end{array}$ & - IS Process [38] \\
\hline $\begin{array}{l}\text { Learning \& } \\
\text { Growth }\end{array}$ & $\begin{array}{c}\text { Future } \\
\text { Orientation }\end{array}$ & $\begin{array}{l}\text { - Talent Management [67] } \\
\text { - Strategic } \\
\text { Competitiveness [53] }\end{array}$ \\
\hline
\end{tabular}






Figure 4. Content related conceptual matrix of 37 articles and 28 IT BSCs

an opportunity to define and spread the corporate strategy (summarized under "Strategy"). A relatively new approach is to use a BSC to balance or prioritize projects, initiatives or contracts (summarized under "Prioritization").

To identify which scorecards link business and IT performance measures - a central facet of BSM - we took a closer look at the perspectives of the IT BSCs. Since the original BSC suggested by Kaplan and Norton has been adapted to IT independently by multiple authors a zoo of similar perspectives with different titles is now available. We therefore derived a mapping, as shown in Table 2, that allowed us to group perspectives according to the four perspectives of the generic IT BSC [60]. We use the generic IT BSC for two reasons: (1) the mapping to the original perspectives is explicitly defined [46] and (2) the generic IT BSC perspectives match the analyzed BSCs to a wider extent than the traditional. To establish this mapping we identified for each adapted IT BSC perspective its original counterpart. Where this linkage was not explicated we attempted to recreate the link according to the perspectives title and the contained metrics. In cases where no appropriate BSC perspective could be identified we introduced additional perspectives to the classification. These were subsequently considered as category for other perspectives unmatchable to the generic IT BSC. We therefore distinguish between four generic IT BSC perspectives and five additional perspectives.

Looking at the first set of perspectives it becomes clear that almost all IT BSCs encompass the traditional perspectives. As these contain business and IT performance measures almost all IT BSCs fulfill the basic precondition to support BSM.

Additional perspectives are applied to host strategically important aspects. A recent example today is the topic of sustainability for which already an 


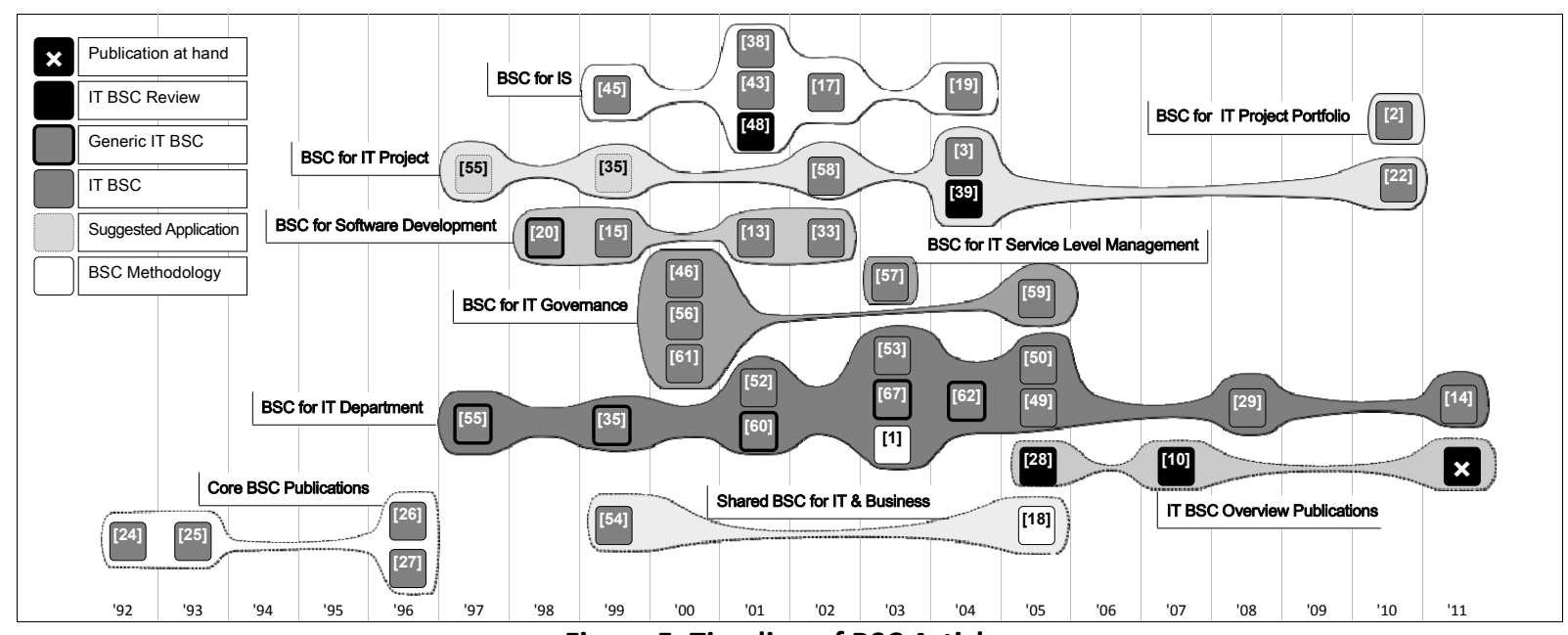

Figure 5. Timeline of BSC Articles

individual IT BSC perspective has been implemented. Scorecards containing mostly business metrics are in some cases extended by an additional "resource" perspective to include technical measures. Furthermore there are single examples of IT BSCs containing perspectives for evaluating project portfolios, uncertainties, and security.

To further evaluate the adaptability of IT BSCs to BSM we examined the linkage between business and technical measures within the selected literature. For this we first selected all IT BSC that provided measurable metrics (summarized under "Metrics"). We continued by selecting IT BSCs from the previous results that contained both business and IT KPIs (summarized under "Business \& IT Metrics"). Finally we narrowed down the selected BSCs to those containing a strategy map linking the previously identified measureable business and IT performance measures.

By identifying the available literature on IT BSCs and classified it according to various characteristics we have established and summarized the current state-ofthe-art in IT BSCs. In the following chapter we now continue to fuse this data to identify those IT BSCs that are most relevant for the adoption of the IT BSC for BSM.

\section{Discussion and research agenda}

We build our analysis on a combination of the "Time Period" characteristic (in a more detailed manner) from Figure 3 and the "Subject of IT BSC" characteristic in Figure 4 resulting in the timeline depicted in Figure 5. The shapes in the diagram group the IT BSCs according to their subjects and represent the attention received within the literature based on the number of publications. This allows us to judge the relevance of IT BSC subjects not only by the number of articles but also by their reoccurrence in time. Thus, even though there are numerous articles suggesting IT BSCs for IS, Software Development and IT Governance no articles were published within last five years. On the contrary, it is apparent that IT BSCs for IT departments and for IT projects seem lively topics that were the first to receive an adapted BSC and are still subject to further research. In order to connect to current research streams, it is essential for newly developed IT BSCs to reference and clearly define its interface to the frequently reoccurring BSCs for IT departments [55] or IT projects [14, 22].

For developing a new BSC for BSM generic IT BSCs may prove especially helpful in offering easy adaptability to new subjects (e.g., business services). These are highlighted in Figure 5 by a thicker outline. The broadly cited generic IT BSC proposed by Van Grembergen is employed multiple times within BSC for the IT department. The most recent version of this BSC can be found in [62].

It is important to note that none of the generic IT BSCs supply a strategy map. This may be due to the fact that strategy maps are specific for a certain application of a BSC. But since highly sophisticated strategy map examples are available for IS [17], for software development [13], and the IT department [52] these should be considered before developing a new IT BSC for BSM.

Also aiding the development of a new IT BSC are reviews in this field of research, which allow a quick identification of available IT BSCs. Reviews are marked black in Figure 5. Apart from the publication at hand a broad overview for practitioners is given in [10] and a scientific review in [48].

To derive an IT BSC for BSM, available BSCs for IS must play a key role in designing perspectives and defining KPIs. Although publications of this kind are over seven years old and do not address current 
strategic issues like sustainability and business orientation, they do successfully address the issue of supporting business IT alignment [19] and evaluating the business value of IT [17].

Taking a distant view at the overall timeline we see a strong decrease in the application of the IT BSC between 2006 and 2009. A possible explanation might be the IT BSC going through the "trough of disillusionment" of a hype cycle as proposed by [10]. However the recent publications may indicate the beginning of the "slope of enlightenment" and again an increasing attention to the usage of the BSC in IT. Additionally the current topic of sustainability [14, 22] may further fuel this development and needs to be considered accordingly for new IT BSCs.

After first establishing the state-of-the-art in IT BSC literature we have now identified the relevant literature for adapting the IT BSC to BSM. In the following paragraph we outline the next steps in creating an IT BSC for BSM as our future research agenda.

\subsection{Research agenda}

For IT service decisions to be taken from a business perspective a tool must be in place evaluating services separately and as a whole according to the strategy of the organization. Although literature is available assessing monolithic IS, so far no service specific IT BSC is available that could be applied or adopted to multiple services.

- As a first research step we therefore suggest the development of a generic BSC for IT services, derived from the generic BSC for IT and the available BSCs for IS.

To evaluate and prioritize services within the context of the overall service network, a concept like the recent BSC for IT project portfolios [2] needs to be adapted for service management.

- As a second research step we therefore suggest the development of a business-oriented BSC for service portfolios. Designed to cascade to the service BSCs it supports the alignment of the service network to the organization's strategy.

For the scorecards from step one and two to work together harmoniously the underlying service architecture needs to be applied when aggregating the data from the service to the portfolio level.

- As a third research step we therefore suggest the development of a method to harness the data of the service architecture to efficiently and accurately aggregate data between various service scorecards and the portfolio applying available "autodiscovery" and "dependency mapping" technologies form BSM [37].

Having outlined our research agenda we now conclude this paper with the limitations of our research and a glance at the future.

\section{Conclusion, limitations and outlook}

With BSM we are witnessing yet another shift in the IT management paradigm resulting from IT services. As IT services are becoming increasingly critical for daily operations the general management demands more transparency and control. However, there are no tools available today that can evaluate the IT service portfolio according to the strategic goals of a company from a business perspective. To identify possible IT BSCs that can be adapted for this task we established the state-of-the-art of IT BSCs. We then continued to identify the relevant starting points for the development of new IT BSCs for BSM. Finally, we sparked the idea of an IT BSC for services and service portfolios to support business-oriented service and service portfolio decision-making.

Although this paper is based on a rigorous literature search we cannot guarantee for its completeness. We are aware that more literature is available on the use of BSCs in IT. If this review was to be extended it could be done so by including and analyzing the results of other reviews [48], conducting a forward search (as described in chapter 3) or updating the conducted searches with results published beyond March 2011. Furthermore the possibilities of analyzing the data collected in this paper are far from exhausted. More insights could be gained by correlating different characteristics identified in Figure 4.

Also, we are fully aware that BSM today in many cases is not much more then the "visual sugar fronting" of an IT service to the business [5]. It has yet to prove its full potential.

But since our vision that controlling IT services from a business perspective is the key to achieve business IT alignment we strive to support this development with useful tools wherever we can.

We hope that our work can support other scholars and practitioners in finding appropriate literature on IT BSCs and wish to have inspired further research regarding the development of the IT BSC. 


\section{References}

[1] Abran, A., Buglione, L.: "A multidimensional performance model for consolidating balanced scorecards", Advances in Engineering Software, Vol. 34, 2003 pp. 339349.

[2] Asosheh, A., Nalchigar, S., Jamporazmey, M.: "Information technology project evaluation: An integrated data envelopment analysis and balanced scorecard approach", Expert Systems with Applications, Vol. 37, 2010 pp. 59315938.

[3] Atkinson, M.: "Measuring the Performance of the IT Function in the UK Health Service Using a Balanced Scorecard Approach", Electronic Journal of Information Systems Evaluation, Vol. 7, 2004 pp. 1-10.

[4] Bartolini, C.: "Business-driven IT Management", pp. 1182. 2009

[5] Cappelli, W.: "Business Service Management Versus Application Performance Monitoring: Conflict and Convergence", pp. 6. 2010.

[6] Cartlidge, A., Hanna, A., Rudd, C., Macfarlane, I., Windebank, J., Rance, S.: An Introductory Overview of ITIL ${ }^{\circledR}$ V3, itSMF Ltd, 2007.

[7] Chand, D., Hachey, G., Hunton, J., Owhoso, V., Vasudevan, S.: "A balanced scorecard based framework for assessing the strategic impacts of ERP systems", Computers in Industry, Vol. 56, 2005 pp. 558-572.

[8] Chilappagari, S.K., Chertkov, M., Vasic, B.: "An Efficient Instanton Search Algorithm for LP Decoding of LDPC Codes Over the BSC.", IEEE Transactions on Information Theory, Vol. 57, 2011 pp. 4417-4426.

[9] Cooper, H.: "Organizing knowledge syntheses: A taxonomy of literature reviews", Knowledge, Technology \& Policy, Vol. 1, 1988 pp. 104-126.

[10] Cram, A.: "The IT Balanced Scorecard Revisited", Information Systems Control Journal, Vol. 3, 2007

[11] Darmawan, B., Cox, K., Ragab, B.: "Business Service Management Best Practices", pp. 188. 2004.

[12] Durraui, T.S., Forbes, S.M., Carrie, A.S.: "Extending the balanced scorecard for technology strategy development", in: Proceedings of the Proceedings of IEEE 2000 pp. 120 - 125.

[13] Eickelmann, N.: "Integrating the Balanced Scorecard and Software Measurement Frameworks", in: Information Technology Evaluation Methods and Management, Wim Van Grembergen, 2001 pp. 240-252.

[14] Erek, K.: "From Green IT To Sustainable Information Systems Management: Managing and Measuring Sustainability In IT Organizations", in: Proceedings of the European, Mediterranean \& Middle Eastern Conference on Information Systems 2011 pp. 1-16.

[15] Ferguson, P., Leman, G., Perini, P., Renner, S., Seshagiri, G.: "Software Process Improvement Works! Advanced Information Services Inc.", pp. 1-35. 1999.

[16] Graeser, V., Pisanias, N., Willcocks, L.P.: Developing the It Scorecard, Business Intelligence Ltd, 1998.

[17] Hagood, W.O., Friedman, L.: "Using the balanced scorecard to measure the performance of your HR information system", Public Personnel Management, Vol. 31, 2002 pp. 543-557.

[18] Hu, Q., Huang, C.D.: "Aligning IT with Firm Business Strategies Using the Balance Scorecard System", in:
Proceedings of the Hawaii International Conference on System Sciences 2005

[19] Huang, C.D., Hu, Q.: "Integrating Web Services with Competitive Strategies: A Balanced Scorecard Approach", Communications of the Association of Information Systems, Vol. 13, 2004 pp. 57-80.

[20] Ibáñez, M.: "Balanced IT Scorecard Description Version 1.0", pp. 1-22. 1998

[21] ISO: INTERNATIONAL STANDARD ISO/IEC 200001 - Information technology - Service management, Geneva, Switzerland, 2005.

[22] Jain, R.P., Benbunan-Fich, R., Mohan, K.: "Assessing Green IT Initiatives Using the Balanced Scorecard", IT Professional, Vol. 13, 2010 pp. 26-32.

[23] Jin, K., Ray, P.: "Business-oriented Development Methodology for IT Service Management", in: Proceedings of the Hawaii International Conference on System Sciences 2008 pp. 1-10.

[24] Kaplan, R.S., Norton, D.: "The balanced scorecard: Measures that drive performance", Harvard Business Review, Vol. 70, 1992 pp. 70-79.

[25] Kaplan, R.S., Norton, D.: "Putting the Balanced Scorecard to Work", Harvard Business Review, Vol. 71, 1993 pp. 134-142.

[26] Kaplan, R.S., Norton, D.: The Balanced Scorecard: Translating Strategy Into Action, Mcgraw-Hill Professional, 1996.

[27] Kaplan, R.S., Norton, D.: "Using the Balanced Scorecard as a Strategic Management System", Harvard Business Review, Vol. 74, 1996 pp. 75-85.

[28] Keyes, J.: Implementing the IT Balanced Scorecard, aligning it with corporate strategy, Auerbach Publications, 2005.

[29] Lee, A.H.I., Chen, W.-C., Chang, C.-J.: "A fuzzy AHP and BSC approach for evaluating performance of IT department in the manufacturing industry in Taiwan", Expert Systems with Applications, Vol. 34, 2008 pp. 96-107.

[30] Levy, Y., Ellis, T.J.: "A Systems Approach to Conduct an Effective Literature Review in Support of Information Systems Research", Informing Science Journal, Vol. 9, 2006 pp. 181-212.

[31] Lewis, E.: "Building Business-Based Service Levels for IT Outsourcing Contracts: The Measure to Manage (M2P) Performance Measurement System", in: Proceedings of the European Conference On Information Systems 2000 pp. 1-8. [32] Machiraju, V., Bartolini, C., Casati, F.: "Technologies for Business-Driven Information Technology Management", in: Extending Web Services Technologies: the Use of MultiAgent Approaches, Cavedon, L., Maamar, Z., Martin, D., Benatallah, B. (eds.), Springer Science+Business Media Inc., New York, 2005 pp. 1-28.

[33] Mair, S.: "A Balanced Scorecard for a Small Software Group", IEEE Software, Vol. 19, 2002 pp. 21-27.

[34] Maltz, A.C., Shenhar, A.J., Reilly, R.R.: "Beyond the Balanced Scorecard: Refining the Search for Organizational Success Measures", Long Range Planning, Vol. 36, 2003 pp. 187-204.

[35] Martinsons, M., Davison, R., Tse, D.: "The balanced scorecard: a foundation for the strategic management of information systems", Decision Support Systems, Vol. 25, 1999 pp. 71-88. 
[36] McNeill, R., Mendel, T.: "IT Asset Management, ITIL, And The CMDB: Paving The Way For BSM", pp. 14. 2005.

[37] Mendel, T., O’Neill, P.: "Implementing BSM - Keep The Big Picture In Mind If You Want To Reap The Full Benefits", pp. 6. 2006.

[38] Meyerson, B.: "Using a balanced scorecard framework to leverage the value delivered by IS", in: Information Technology Evaluation Methods and Management, Wim Van Grembergen, 2001 pp. 212-230.

[39] Milis, K., Mercken, R.: "The use of the balanced scorecard for the evaluation of Information and Communication Technology projects", International Journal of Project Management, Vol. 22, 2004 pp. 87-97.

[40] O’Neill, P.: "BSM Is Coming Of Age: Time To Define What It Is", pp. 4. 2006.

[41] O’Neill, P., Evelyn, H.: "The Forrester Wave" Business Service Management, Q1 2007", pp. 16. 2007.

[42] Pelzer, U., Schwaner, I., Stieler, J., Adler, M., Seraphin, J., Dörken, B., Riess, H., Oettle, H.: "Best supportive care (BSC) versus oxaliplatin, folinic acid and 5-fluorouracil (OFF) plus BSC in patients for second-line advanced pancreatic cancer: a phase III-study from the German CONKO-study group.", European Journal Of Cancer (Oxford, England: 1990), Vol. 47, 2011 pp. 1676-1681.

[43] Rosemann, M.: "Evaluating the Management of Enterprise Systems with the Balanced Scorecard", in: Information Technology Evaluation Methods and Management, Van Grembergen, W. (ed.), 2001 pp. 171-184.

[44] Rosemann, M., Fielt, E., Kohlborn, T., Korthaus, A.: "Business Service Management", pp. 1-15. 2009.

[45] Rosemann, M., Wiese, J.: "Measuring the Performance of ERP Software - a Balanced Scorecard Approach", in: Proceedings of the Australasian Conference on Information Systems 1999 pp. 773-784.

[46] Saull, R.: "The IT Balanced Scorecard - A roadmap to effective governance of a shared services IT organization", Information Systems Control Journal, Vol. 2, 2000 pp. 31-38. [47] Sauvé, J., Moura, A., Sampaio, M., João, J., RadziukEduardo: "An Introductory Overview and Survey of Business-Driven IT Management", in: Proceedings of the International Workshop on on business-driven IT management 2006 pp. 1-10.

[48] Sedera, D., Gable, G., Rosemann, M.: "A Balanced Scorecard Approach to Enterprise Systems Performance Measurement", in: Proceedings of the Australasian Conference on Information Systems 2001 pp. 1-12.

[49] Simon, S.J.: "Balanced Scorecard: A Tool to Improve IS Department Planning and Evaluation", Journal of Information Technology Case and Application Research, Vol. 7, 2005 pp. 1-23.

[50] Son, S., Weitzel, T., Laurent, F.: "Designing a ProcessOriented Framework for IT Performance Management Systems", The Electronic Journal Information Systems Evaluation, Vol. 8, 2005 pp. 219-228.

[51] Staehr, L.: "Assessing Business Benefits from ERP Systems: An Improved ERP Benefits Framework", in: Proceedings of the International Conference on Information Science 2007 pp. 1-17.

[52] Stewart, R.A., Mohamed, S.: "Utilizing the balanced scorecard for IT/IS performance evaluation in construction",
Journal of Construction Innovation, Vol. 3, 2001 pp. 147163.

[53] Stewart, R.A., Mohamed, S.: "Evaluating the value IT adds to the process of project information management in construction", Automation in Construction, Vol. 12, 2003 pp. 407-417.

[54] Van der Zee, J.T.M., Jong, B.d.: "Alignment is not enough: Integrating business and information technology management with the balanced business scorecard", Journal of Management Information Systems, Vol. 16, 1999 pp. 137156.

[55] Van Grembergen, W.: "Measuring and improving corporate information technology through the balanced scorecard technique", in: Proceedings of the European Conference On Information Technology 1997 pp. 1-18.

[56] Van Grembergen, W.: "The Balanced Scorecard and IT Governance", Information Systems Control Journal, Vol. 2, 2000 pp. $40-43$.

[57] Van Grembergen, W.: "Using COBIT and the Balanced Scorecard as Instruments for Service Level Management", Information Systems Control Journal, Vol. 4, 2003

[58] Van Grembergen, W., Amelinckx, I.: "Measuring and Managing E-business Projects through the Balanced Scorecard", in: Proceedings of the Hawaii International Conference on System Sciences 2002 pp. 152-168.

[59] Van Grembergen, W., Haes, S.D.: "Measuring and Improving IT Governance Through the Balanced Scorecard", Information Systems Control Journal, Vol. 2, 2005 pp. 1-8.

[60] Van Grembergen, W., Saull, R.: "Aligning Business and Information Technology through the Balanced Scorecard at a Major Canadian Financial Group: its Status Measured with an IT BSC Maturity Model", in: Proceedings of the Hawaii International Conference on System Sciences 2001 pp. 1-10. [61] Van Grembergen, W., Saull, R.: "Information technology governance through the balanced scorecard", in: Information Technology Evaluation Methods and Management, Van Grembergen, W. (ed.), 2001 pp. 199-211. [62] Van Grembergen, W., Saull, R., Haes, S.D.: "Linking the IT Balanced Scorecard to the Business Objectives at a Major Canadian Financial group", in: Strategies for Information Technology Governance, 2004 pp. 129-151.

[63] Van Grembergen, W., Timmerman, D.: "Monitoring the IT process through the balanced score card", in: Proceedings of the Information Resources Management 1998 pp. 105116.

[64] Vom Brocke, J., Simons, A., Niehaves, B., Riemer, K., Cleven, A., Plattfaut, R.: "Reconstructing the Giant: On the Importance of Rigour in Documenting the Literature Search Process", in: Proceedings of the European Conference On Information Systems 2009 pp. 2206-2217.

[65] Webster, J., Watson, R.T.: "Analyzing the past to prepare for the future: Writing a literature review", MIS Quarterly, Vol. 26, 2002 pp. xiii-xxiii.

[66] Winniford, M., Conger, S., Erickson-Harris, L.: "Confusion in the Ranks: IT Service Management Practice and Terminology", Information Systems Management, Vol. 26, 2009 pp. 153-163.

[67] Working Council for Chief Information Officers: IT Balanced Scorecards End-to-End Performance Measurement for the Corporate IT Function, 2003. 